Errata

\title{
Arcanobacterium abortisuis sp. nov., isolated from a placenta of a sow following an abortion
}

Ryozo Azuma, Satoshi Murakami, Akihiro Ogawa, Yoshikiyo Okada, Shigeru Miyazaki and Takashi Makino

International Journal of Systematic and Evolutionary Microbiology (2009), 59, part 6, 1469-1473

Due to an error introduced during copy-editing, in the section discussing analysis of wholecell sugars on p. 1470 (left column, third paragraph), the concentration of $\mathrm{H}_{2} \mathrm{SO}_{4}$ is given incorrectly as $2 \mathrm{M}$. The correct concentration is $0.5 \mathrm{M}$. The authors also wish to add that this treatment was carried out at $100{ }^{\circ} \mathrm{C}$ for $2 \mathrm{~h}$, before adjustment to $\mathrm{pH} 5.0-5.5$ with saturated $\mathrm{Ba}(\mathrm{OH})_{2}$.

\section{Chromobacterium piscinae sp. nov. and Chromobacterium pseudoviolaceum sp. nov., from environmental samples}

Peter Kämpfer, Hans-Jürgen Busse and Holger C. Scholz

International Journal of Systematic and Evolutionary Microbiology (2009), 59, part 10, 2486-2490

The type strain of Chromobacterium pseudoviolaceum is given erroneously in the abstract and species description as NCTC 8182. The correct type strain of Chromobacterium pseudoviolaceum is LMG $3953^{\mathrm{T}}=\mathrm{CCM} 2076^{\mathrm{T}}=\mathrm{NCIMB} 8182^{\mathrm{T}}$. The authors are grateful to Peter Dawyndt (LMG Gent) for pointing out this error. 